\title{
El efecto del exilio en las obras de Juan José Saer y Daniel Moyano. Propuesta metodológica para analizar procesos redaccionales y de archivo
}

\author{
DIEGO VIGNA Universidad Nacional de Córdoba - CONICET, Argentina / diegovigna@gmail.com \\ VERÓNICA BERNABEI Université de Poitiers - CRLA-Archivos, Francia / veronicabernabei@hotmail.com
}

\section{Resumen}

Este trabajo se centra en las obras y los archivos de Juan José Saer y Daniel Moyano, a partir de algunos interrogantes y de una propuesta metodológica en torno a los procesos escriturales y de archivación que tienen como cuestión de fondo el efecto del exilio en la obra de un autor. A la hora de analizar dichos procesos utilizando como punto de partida un archivo de obra, encontramos que una disposición en el espacio de los datos permite comprender hiatos o blancos que se destacan en una cronología establecida a partir de la lectura. Estas reflexiones se sostienen, por tanto, en una indagación sobre la temporalidad de la escritura y su materialización a partir de un dimensionamiento espacial de los documentos. Nos preguntamos cómo es posible ver la escritura; esto es, cómo se pueden representar y explicar, en el espacio, las vicisitudes literarias, editoriales y vivenciales que conforman el recorrido de un escritor. Y a partir de esto, cómo es posible ver la evolución de un archivo a medida que los investigadores intervienen los documentos.

Para responder a los interrogantes proponemos articular documentos pre-redaccionales y redaccionales inventariados y organizados que conforman nuestro objeto «literario» con otros documentos, fechas y datos contextuales en torno a los autores. Lo hacemos partiendo de un modelo gráfico que elaboramos para dilucidar los procesos redaccionales en la obra de Saer, en principio, y que luego extendimos a la escritura y el archivo de Moyano. Las dos cronologías permiten ver la incidencia que puede tener la constitución de un fondo documental para ampliar o desocultar distintas facetas o períodos de producción.

Palabras clave: procesos redaccionales / archivo de escritor / mapa de génesis de escritura / Juan José Saer / Daniel Moyano

\section{The effect of exile in works of Juan José Saer} and Daniel Moyano. Methodological proposal to analyze writing and archival processes

Abstract

This article focuses on the works and archives of Juan José Saer and Daniel Moyano. The general idea was to address specific questions through a methodological proposal about archival and writing processes based on the effect of exile in the work of an author as a fundamental issue. Using an archival work as a starting point, we found that the spatial disposition of the data allows us to understand the hiatus or blanks that stand out in a chronology established from the reader perspective. Therefore, these reflections are sustained in an inquiry about the temporality of writing and its materialization from a spatial disposition of documents. In this context, we wonder how it is possible «to see» the writing; how the literary, editorial and experiential vicissitudes of a writer could be represented and explained in a graphical space model. And from this, how it is possible to see the evolution of an archive as the researchers intervene the documents.

To answer these questions we propose to articulate 
inventoried and organized pre-editorial and editorial documents together with other documents, dates and contextual data about the authors. To this end and starting from a graphical model elaborated to elucidate the writing process in the work of Saer, we extended it to the writing and archive of Moyano. These two chronologies allowed us to point out the influence that a documentary collection could have on expand or uncover different production aspects or periods.

Key words: writing processes / writer's archive / writing genesis map / Juan José Saer / Daniel Moyano

Recibido: 25/6/2018. Aceptado: 6/9/2018

Para citar este artículo: Vigna, Diego y Bernabei, Verónica (2018). El efecto del exilio en las obras de Juan José Saer y Daniel Moyano. Propuesta metodológica para analizar procesos redaccionales y de archivo. $E l$ taco en la brea, 8 (junio-noviembre), 32-53. Santa Fe, Argentina: UNL. DOI: 10.14409/tb.v1i8.775 


\section{Introducción}

En un ensayo de 1963, Augusto Roa Bastos imaginó una selección de escritores del interior argentino que, llamativa y casi tristemente, habría de convertirse años después en una selección del exterior. En el prólogo al segundo libro de cuentos de Daniel Moyano, La lombriz, Roa Bastos destacó a un grupo de jóvenes que había comenzado a publicar en los márgenes de Buenos Aires hacia 1960, conformado por Moyano, Antonio Di Benedetto, Héctor Tizón y Juan José Saer. Ese era, en aquel momento, el único punto de contacto entre ellos. Luego, entre 1968 y el advenimiento de la última dictadura en Argentina, los cuatro terminaron por construir obras dispares e importantes desde esa zona siempre incómoda y discutida que es el exilio.

Los «avatares» de tal zona, por decirlo de un modo liviano, se escriben, de una u otra manera, en presente continuo. En este contexto, el papel de los archivos de escritores se revela como una dimensión clave porque el acceso a esos materiales, de la misma manera que a un conjunto heterogéneo de documentos que permiten dilucidar cómo un escritor leía y escribía, devela dinámicas transtextuales tanto internas como externas a las obras y estimula posibles hipótesis de lectura. En un archivo de escritor, el espesor de cada texto se superpone, se entremezcla con el de otros textos; algunos de ellos han esperado mucho tiempo en cajones antes de ser publicados (las razones históricamente han sido editoriales, personales, políticas), otros se revelan inconclusos o tentativos, lo que redistribuye la información sobre cada obra y su cronología. Cronología que siempre será conjetural, y estará abierta a la duda de lo que está y de lo que podría faltar.

De los cuatro escritores convocados por Roa Bastos en aquel ensayo, hasta el momento sólo se han conocido los manuscritos de Moyano y de Saer. Esta es la razón-base por la que aquí nos ocuparemos de ellos, a partir de algunas preguntas guía y de una propuesta metodológica en torno a los procesos escriturales que tienen como cuestión de fondo el efecto del exilio en la obra de un autor. A la hora de analizar dichos procesos utilizando como punto de partida un archivo de obra, encontramos que muchas veces una disposición en el espacio de los datos recabados (y por tanto de los interrogantes o certezas que surgen al abordar un corpus extenso de documentos) permite comprender los hiatos o blancos que se destacan en una cronología establecida a partir de la lectura. Es así que estas reflexiones se sostienen en una indagación sobre la temporalidad de la escritura, y su materialización a partir de un dimensionamiento espacial de los documentos con los que contamos.

El exilio perturba las cronologías, tanto de Moyano como de Saer. Y en estos dos casos hemos podido observar que, desde contextos políticos, puntos geográficos y búsquedas estéticas distintas, el efecto del exilio se manifiesta, como afirmó Marcelo Casarin (2017), en escrituras desterradas y deslenguadas.

\section{Temporalidad de la escritura, temporalidad de un archivo: un modelo gráfico}

A partir del trabajo que realizamos con los archivos de Saer y de Moyano nos preguntamos cómo es posible ver la escritura de un autor; esto es, cómo se pueden representar, en el espacio, las vicisitudes literarias, editoriales y vivenciales que conforman el recorrido de un escritor. Y a partir de esto, cómo sería posible ver un archivo: su evolución, sobre todo a medida que los investigadores (nuestro trabajo, en este caso) intervienen los documentos. ¿Sirve para algo, desde la perspectiva de la crítica y de la genética textual, ver escrituras y archivos? ¿Cómo se puede alimentar el análisis al comparar un modelo de visibilización de procesos escriturales que se aplique también a los procesos y descubrimientos que marcan la evolución de un archivo? 
Para responder a estos interrogantes proponemos, como es costumbre en el campo de los estudios crítico-genéticos, articular los documentos pre-redaccionales y redaccionales' inventariados y organizados que conforman nuestro objeto «literario» con otros documentos, fechas y datos contextuales en torno a los autores. Lo hacemos partiendo de un modelo gráfico que elaboramos para dilucidar los procesos redaccionales en la obra de Juan José Saer, en principio, y que luego extendimos a la escritura y el archivo de Daniel Moyano. Estas dos cronologías permiten ver, por sus propias características, la incidencia que puede tener la constitución de un fondo documental de autor para ampliar o desocultar distintas facetas o períodos de producción.

El modelo, al que llamamos mapa de génesis de proyectos de escritura, representa entonces una cronología espacializada del tiempo de maduración de cada proyecto redaccional. Y aunque busca ofrecer una mirada en cierto modo panorámica de los proyectos, no es ni lineal ni fijo y llama a ser modificado a medida que los estudios sobre los archivos de cada autor se van profundizando. Esta propuesta fue concebida a partir de preguntas que interpelan los recursos metodológicos de la crítica genética: ¿qué puede mostrar un mapa así, y cómo lo muestra? Es decir, ¿qué criterios de inclusión y de exclusión definen sus límites, y cómo representarlos? ¿Se incluye o se excluye la distinción entre fase pre-redaccional y redaccional?; ¿cómo sería posible representar, por ejemplo, los proyectos abandonados y luego retomados por los autores: hacen parte del mismo proceso de génesis o deben ser considerados como dos momentos diferentes?

Para la representación gráfica del mapa elegimos partir de un eje cartesiano que ordena los datos a partir de años. Con el fin de hacer visual esta cronología, la abscisa y la ordenada cargan el mismo dato: los años que van desde la génesis del primer proyecto de autor hasta el último que ha sido publicado. $\mathrm{Al}$ «cargar» las fechas (algunas precisas, algunas aproximativas, según los datos a disposición o según la deducción que se pueda realizar a partir de otros documentos contextuales) de los inicios y los finales de la escritura de los textos se generan cuadrados que dan cuenta de esas «zonas» en las que los autores fueron trabajando, rumiando sus textos. Las fechas de publicación son indicadas a partir de un punto del mismo color que el cuadrado correspondiente a la textualización de cada obra. Esto nos permite ver la distancia entre los periodos de escritura y el momento en que el texto deviene público.

Los criterios de elaboración y de exploración de cada mapa están directamente ligados a las particularidades del archivo y del material contextual o periférico (ya sea producido por el escritor o por la recepción de la obra). El dilema al cual nos vimos enfrentados al momento de dar forma a los respectivos mapas fue el de decidir si separábamos o no la fase pre-redaccional de la fase redaccional; en el caso de Saer, tal información no es homogénea, la temporalidad de cada fase del proyecto se confunde y deviene un gran periodo en la cronología. ${ }^{2}$

En lo que concierne al caso Moyano, este dilema fue aún más profundo porque la magnitud de la falta de material genético es mucho mayor, aunque por esas mismas razones también es iluminadora. Moyano fue inducido a abandonar el país en 1976, apenas días después de la irrupción dictatorial y luego de haber sido encarcelado. Con su partida forzada desapareció casi todo el material genético que conservaba en su domicilio de La Rioja (Argentina), incluyendo casi todos sus libros de cuentos y dos o tres novelas. Vale recordar que el periodo riojano fue el más productivo en la literatura de Moyano, lo que además lleva a complejizar aún más el dilema expuesto porque, como veremos, la producción posterior a su radicación en Madrid incluye en gran parte una suerte de reescritura de los textos «argentinos». 
En los dos casos es la imagen, la forma del archivo, lo que nos permitió tomar una decisión metodológica. En el caso de Saer, la continuidad intrínseca de la escritura observable en el archivo. En el caso de Moyano, la ausencia de documentos que respalden toda fase pre-redaccional de sus textos publicados en Argentina, articulada con la iluminadora ampliación del archivo a partir de su producción heteróclita. Esto es, la inclusión, junto al fondo documental digitalizado originalmente, de su archivo de fotografías, sus notas periodísticas del periodo riojano (1959-1976) y la exhumación de sus viejos disquetes informáticos utilizados en Madrid (1987-1990), obsoletos en la actualidad.

De este modo, en ambos casos decidimos no diferenciar las fases redaccional y pre-redaccional porque claramente no existe esta información para todos los textos, y porque en muchos casos tal diferenciación sería intervenir sobre un proceso genético mucho más complejo y, en algunos ejemplos, irresoluble. Destacamos esto porque, en el caso de Saer, existe en numerosos cuadernos de su archivo la convivencia de varios procesos de génesis simultáneos, en diferentes estados de maduración; existen también núcleos narrativos que reaparecen a lo largo de los años, buscando un lugar, una textualización posible, ${ }^{3}$ y existen proyectos que mutan y que abren nuevas brechas en el tiempo de la diégesis de la Zona. ${ }^{4}$ Mientras que en el caso de Moyano, la complejidad se acentúa por los obstáculos y los silencios creativos que su itinerario existencial ha desencadenado. A la casi total ausencia de documentos genéticos correspondientes a sus libros editados antes de 1981 se suman algunos ejemplos singulares que son difíciles de encuadrar en este análisis: Tres golpes de timbal, novela que comenzó a escribir en 1985, encuentra su germen temático y narrativo en anotaciones de un cuaderno fechado en 1976, que sí logró viajar de Argentina a España; El vuelo del tigre, novela publicada en 1981, resultó ser según otros documentos periféricos (entrevistas, aclaraciones autorales) la supuesta reescritura de un texto producido entre 1974 y 1976 en La Rioja, denominado El salvador, y enterrado en una huerta para no sufrir las represalias del terrorismo de Estado. A estos ejemplos se suman otros que profundizaremos, y que nos llevaron a desentendernos de la separación entre fases redaccionales y pre-redaccionales.

De modo que pensar los procesos de escritura de obra en términos de mapa permite resaltar las temporalidades que lo conforman de la misma manera que los vacíos que configuran y reconfiguran la totalidad de la producción del autor. La exploración del mapa se realiza en el umbral entre el análisis literario y la crítica genética, ya que la lectura de los espacios del mapa debe completarse necesariamente con el material archivado, con el material publicado y con la recepción de la obra (entrevistas o artículos críticos, periodísticos, etc.).

La exploración de un mapa de génesis de proyectos de escritura nos permite reconocer inclusiones y exclusiones, desplazamientos y reestructuraciones. Por ejemplo, en el caso de Saer, la influencia del contexto sociohistórico inmediato en la redacción de ciertos textos. Los ejemplos más notables son los libros Responso, Cicatrices y El entenado. ${ }^{5}$ En el caso de Moyano, los ejemplos citados hablarán de esto, a los que podríamos sumar la singular relación que estableció con los dispositivos informáticos de procesamiento de textos para encarar un ambicioso proceso de reescritura de su obra.

\section{El caso Saer. Ejemplos de una escritura incesante}

Juan José Saer, escritor santafesino nacido en 1937, murió en París en 2005 escribiendo La grande, su última novela. La escritura saeriana se presenta desde la preparación de su primer libro de 
cuentos (En la zona, 1960) como un continuo narrativo; es decir, una escritura casi sin interrupciones. ${ }^{6}$ La continuidad entre los proyectos es claramente visible en el mapa, que revela un ritmo dado por superposiciones y encadenamientos escriturarios. Presentamos a continuación la lista de obras incluidas en el mapa de génesis, ordenadas por fecha de publicación.

\begin{tabular}{|c|c|c|c|}
\hline Publicado en & Título y acrónimo & Proceso genético & Lugar de edición y editorial \\
\hline 1960 & En la zona (ELZ) & $1957-1960^{7}$ & Santa Fe, Editorial Castellví \\
\hline 1964 & Responso (R) & $1963-1964$ & Buenos Aires, Jorge Álvarez \\
\hline 1965 & Palo y hueso (PyH) & $1960-1961$ & Buenos Aires, Camarda Junior \\
\hline 1966 & La vuelta completa (LVC) & $1961-1963$ & Santa Fe, Biblioteca Popular C. C. Vigil \\
\hline 1967 & Unidad de lugar (UdL) & $1965-1966$ & Buenos Aires, Galerna \\
\hline 1969 & Cicatrices (Cic.) & 1967 & Buenos Aires, Sudamericana \\
\hline 1974 & El limonero real (ELR) & $1963-1972$ & Barcelona, Planeta \\
\hline 1976 & La mayor (LM) & $1969-1975$ & Barcelona, Planeta \\
\hline 1977 & & $1960-1975$ & Caracas, Fundarte \\
\hline 1988 & El arte de narrar (EAdN) & 1960-1971/1976-1982 & Santa Fe, Univ. Nac. del Litoral \\
\hline 2000 & & $1981-1987$ & Buenos Aires, Seix Barral \\
\hline 1980 & Nadie nada nunca (NNN) & $1971^{\star} / 1973-1978^{8}$ & México, Siglo XXI \\
\hline 1983 & El entenado (EE) & $1979-1982$ & Buenos Aires, Folios \\
\hline 1986 & Glosa (Gl) & $1978^{\star} / 1982-1986^{9}$ & Buenos Aires, Alianza \\
\hline 1988 & La ocasión (LO) & $1960^{\star} / 1977^{\star} / 1987$ & Buenos Aires, Alianza \\
\hline 1991 & El rio sin orillas (ERsO) & 1991 & Buenos Aires, Alianza \\
\hline 1993 & Lo imborrable (LI) & $1976 * / 1980-1993$ & Buenos Aires, Alianza \\
\hline 1994 & La pesquisa (LP) & 1993-1994 & Buenos Aires, Seix Barral \\
\hline 1997 & Las nubes (LN) & 1994-1997 & Buenos Aires, Seix Barral \\
\hline 2000 & Lugar (L) & $1983-2000$ & Buenos Aires, Seix Barral \\
\hline 2000 & Esquina de febrero (EdF) & 1964-1965 & Buenos Aires, Seix Barral \\
\hline 2005 & La grande $(\mathrm{LG})$ & 1985-2005 & Buenos Aires, Seix Barral \\
\hline
\end{tabular}

Nos centraremos en el análisis del año transcurrido entre 1968 y1969, período en el que Saer parte de la Argentina. Para ese entonces ya había publicado cinco obras, ${ }^{10}$ había terminado la escritura de su tercera novela titulada Cicatrices, ${ }^{11}$ y se encontraba redactando la novela El limonero real que terminaría en 1972 para ser publicada en 1974. Fuera de esta redacción, ningún material indica que entre 1968 y 1969 estuviese escribiendo otros textos finalmente publicados. De hecho, las obras que consolidan lo que la crítica califica como «los mejores años Saer» no comenzarían a escribirse (y esto de manera espaciosa) hasta fines de 1969.

En el primer mapa (detalle del periodo 1957-1979) se observa que entre 1968 y 1969 hay un vacío narrativo, ${ }^{12}$ en el que no encontramos trazas de proyectos literarios a no ser por El limonero real, 


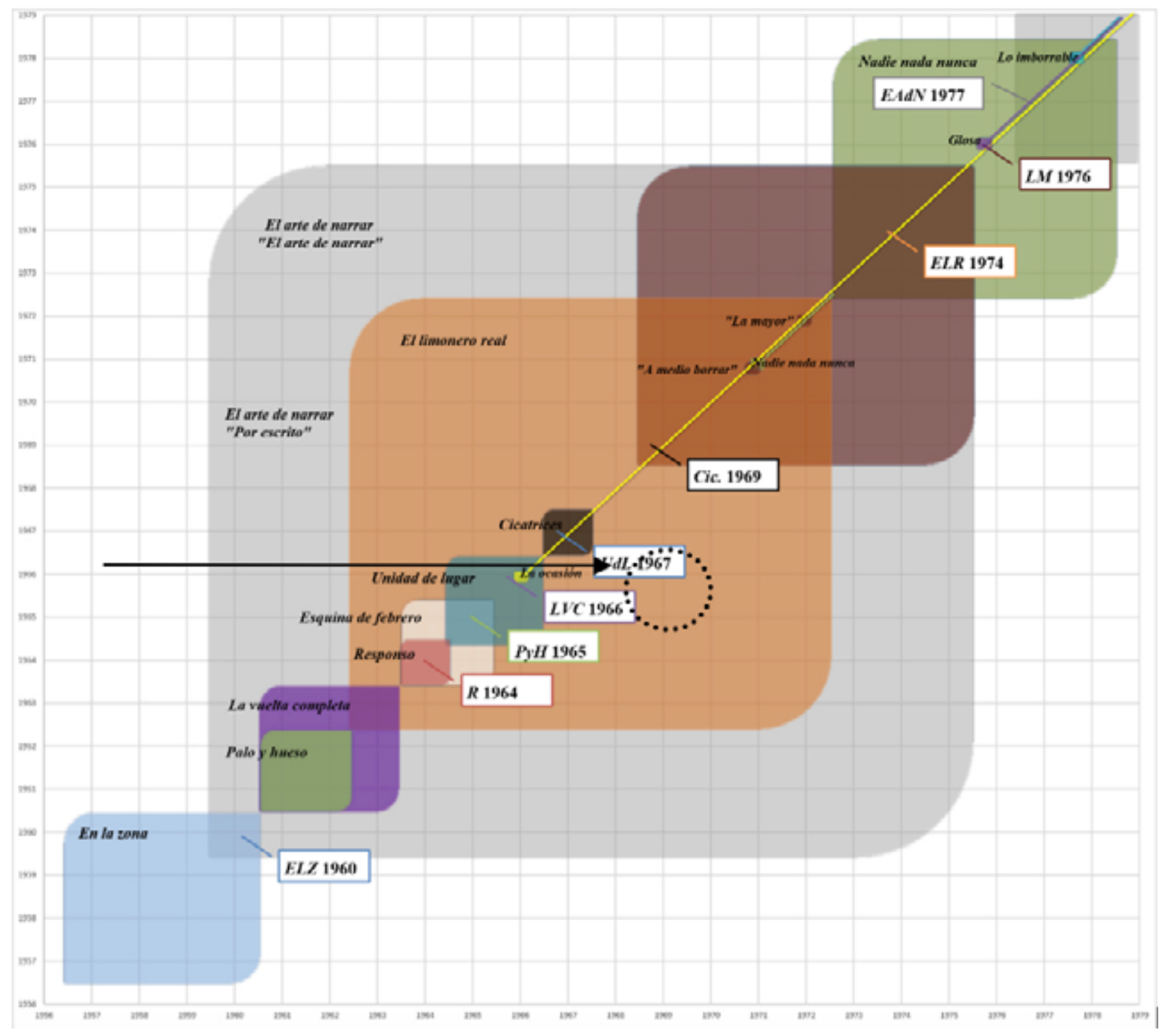

Detalle del mapa: período 1957-1979

cuya redacción difícil e intermitente se ve justamente modificada luego de este período. Esta época es interesante por dos razones: en primer lugar, porque se trata del momento en que Saer abandona su país de origen para radicarse en Francia; en segundo término, porque tal evento provoca un cambio radical en la concepción de la escritura y, por lo tanto, en la forma de la obra.

Entre los papeles conservados en el Archivo Saer existen tres grupos que contienen documentos redactados en esta época: dos cuadernos («Cuaderno 7» y «Cuaderno núcleo I»), y hojas reagrupadas bajo el título de «Hojas sueltas I (fines de los 60 y años 70)»13 que contienen notas, poemas, ensayos y textos breves biográficos. Tal contenido testimonia una escritura que podríamos llamar «repentina»; el desarraigo allí adquiere la forma de una escritura inmediata, breve y anclada en la experiencia del presente no ya como experiencia estética sino como extrañamiento.

Si la obra literaria de Saer se destaca fundamentalmente por su producción novelística, en el mapa se ve que en estos años, y hasta 1973, la forma novela es abandonada. La escritura se desvía de la «forma larga" porque requiere una distancia con respecto a lo narrado que la experiencia presente del desarraigo no otorga. Es por esto que nos preguntamos si el vacío narrativo entre 


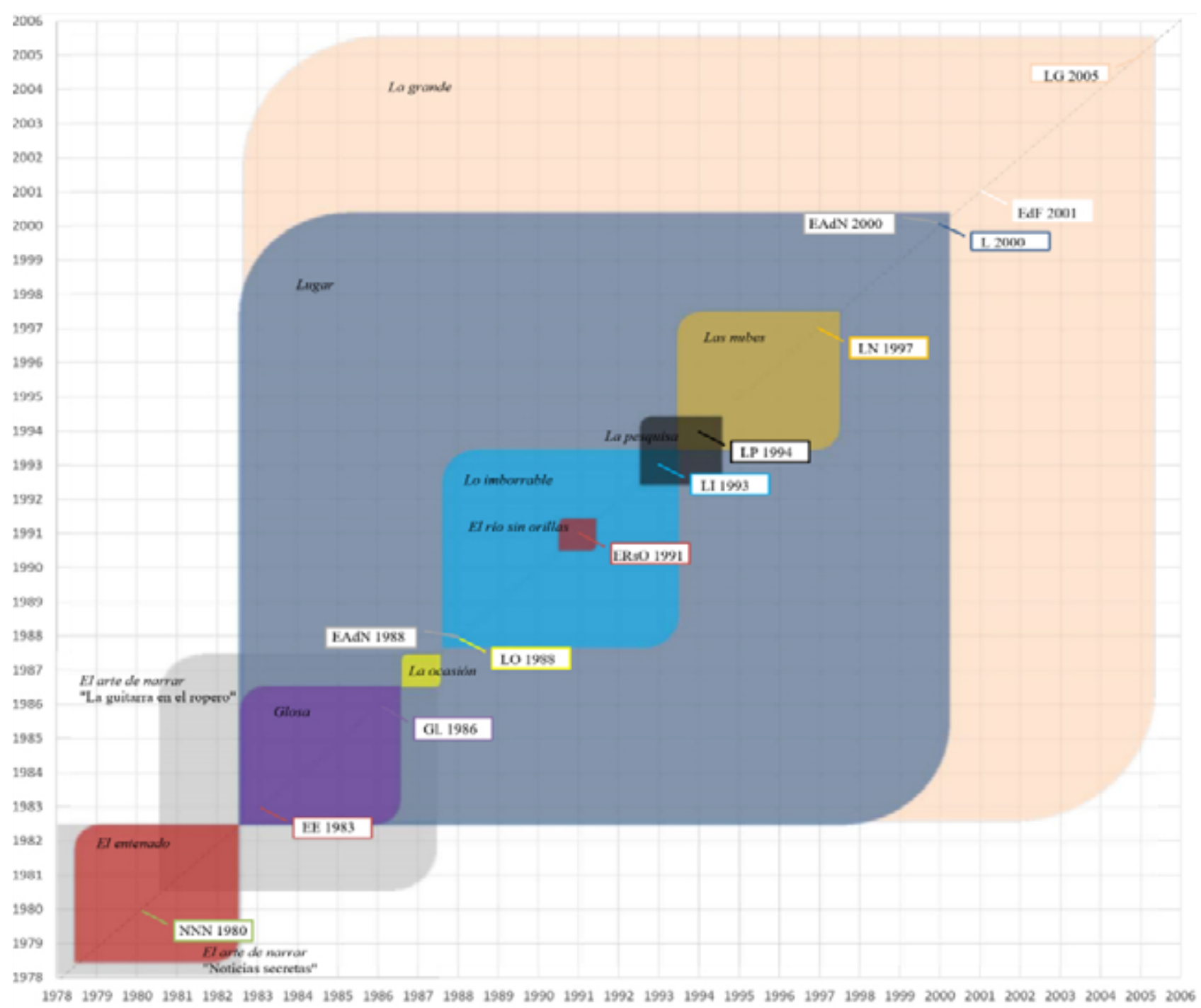

Detalle del mapa: período 1957-1979

1968 y 1969 remite a un rechazo o a una imposibilidad de la escritura de la novela; entre las notas breves, los poemas, los borradores de ensayos escritos durante los primeros años de residencia en Francia, encontramos dos proyectos novelísticos sin aparente continuidad: «Las aventuras de Carlos Tomatis» y «Continuo». El análisis de ese material nos llevó a inclinarnos por la segunda hipótesis: la experiencia del desarraigo conlleva la imposibilidad de la escritura de la «forma larga novela», algo que veremos más radicalizado aún en Moyano.

A continuación presentamos algunas notas para dar cuenta de cómo la desfamiliarización del entorno, esto es, la experiencia del extranjero, provoca a la vez el deseo y el fracaso de la escritura, preparando sin embargo el terreno de la novela a venir, de la forma novela a venir que será la textualización de una distancia irrecuperable desde ese momento y en adelante. ¿Cómo se puede leer esto? Guardando (creemos) cierta distancia con las lecturas teleológicas o interpretativas de la obra para explotar lo que caracteriza a todo borrador: lo inacabado, lo interrumpido, lo abandonado, lo fragmentario. Partimos de lo que Anne Herschberg Pierrot llama «la escritura suspendida», una suspensión que no es sólo abandono de la escritura sino también manifestación de un proceso. 
El acento estaría sobre el espacio que se crea entre la carencia (la interrupción de la escritura) y la proyección (la potencialidad de lo escrito), el futuro indeterminado de los documentos del archivo, la potencialidad de una obra otra (Herschberg:123-125). Si se lee desde la certeza de lo inacabado, lo que se lee no es la obra (en tanto intención del autor) sino una potencialidad de la escritura abierta a un indefinido número de interpretaciones. Leer el archivo es, en este sentido, no solo tener acceso a documentos que cierran escenas de lectura de la obra editada, sino también leer una poética indeliberada de lo descartado. De este modo, la lectura desde el archivo permite concebir la obra desde lo potencialmente infinito, no solo porque revela una estructura compleja y multitemporal de ésta, sino porque la lectura de esa masa de documentos representa un estado latente.

En el «Cuaderno núcleo I», luego de un texto breve en el que Saer manifiesta la imposibilidad de escribir y de leer, encontramos la siguiente nota para el proyecto titulado «Plan para una novela: "Las aventuras de Carlos Tomatis"»:

\section{ANOTACIÓN DEL 2 DE JULIO DE 1968}

Domingo: el mismo propósito de orden y de trabajo. Pero esta vez lo cumpliré. Ya casi no puedo leer, y si leo, entiendo cada vez menos lo que leo. (...) Si no comienzo otra vez a dominar mis impulsos de destrucción y dispersión (¿Cuándo, me pregunto, los dominaré?) soy hombre al agua. Hasta ahora, me doy cuenta, mis obras han sido hijas de la facilidad. Es cuando el trabajo se empieza a poner difícil cuando ha llegado para un escritor el momento de probar y probarse quién es. Este mes cumplo treinta y un años. No hacer caso de los sueños, admitir esta realidad pétrea y trabajar. A esto llamaban los antiguos la madurez. (2012:309)

Escribirse a sí mismo es luchar contra la dispersión y la destrucción de la escritura, a partir de la escritura. Es un campo de fuerza en donde el caos de la experiencia se manifiesta en la imposibilidad de leer, de comprender y también en la imposibilidad de escribir. Pero al mismo tiempo, se trata de un texto vitalista, de fuerte interpelación personal, a la vez profesional («probarse quién es» en tanto escritor) y privada (la urgencia de la edad manifestada en la frase «Este mes cumplo treinta y un años»).

Las últimas líneas renuevan la forma del párrafo porque la interpelación a la escritura se vuelve imperativa, el Saer de esos años necesitaba «admitir (...) y trabajar». El autor se exige un pasaje a la acción, al orden de la escritura que parece ser la dificultad más grande. El siguiente texto se encuentra inmediatamente después de la anotación anterior. En la búsqueda de la escritura, se esquematiza la novela por venir:

Plan para una novela: «Las aventuras de Carlos Tomatis». Su estructura sería la siguiente: pequeños fragmentos, como los pequeños poemas en prosa de Baudelaire, unidos entre sí no por la acción —o la trama- sino por la constante del personaje, por la serie de acontecimientos que vive — separados, anecdóticamente unos de otros, pero unidos por su significación-y por ciertos símbolos conocidos por todos, que reaparecen una y otra vez a lo largo de los fragmentos (otro título posible). La obra abarcaría desde el despertar de Tomatis hasta su sueño nocturno, a la noche siguiente. (2012:309)

Este «plan» contiene el germen de lo que muchos años más tarde sería la novela de Carlos Tomatis, Lo imborrable (1993). Reconocemos no solo la figura de Tomatis que es en los dos casos protagonista, sino también la planificación de la estructura fragmentaria propia a Lo imborrable. ${ }^{14}$ 
Dada la distancia temporal entre esta cita y el trabajo pre-redaccional de la novela (a partir de 1988), podemos afirmar que se trata de un núcleo persistente, propio de la forma de la escritura en Saer. A lo largo de sus cuadernos encontramos en repetidas ocasiones fragmentos, imágenes, núcleos narrativos que como la ritournelle de Deleuze, vuelven cíclicamente hasta encontrar su forma definitiva. En muchos casos, la escritura suspendida e inacabada encuentra, años después, una de sus proyecciones posibles y se suma a la obra.

De esta manera, las persistencias en Saer no solo se manifiestan en un espacio diegético recurrente y en una lengua propia, sino también (y esto es visible desde la apertura del archivo) desde imágenes, fragmentos, núcleos latentes que aunque no encuentren su lugar, van modelando la forma de la obra. Es solo a partir de los documentos del archivo que esto se puede observar; la temporalidad de las persistencias (que es, en cierto modo, la temporalidad de lo inacabado) explica no ya la obra publicada, sino una forma de la escritura, un ritmo vital.

En «Hojas sueltas I», luego de un poema sobre el silencio en París y de algunas notas para un proyecto de novela titulado «Continuo» (que presentamos luego), encontramos el siguiente texto:

\section{EL PARAÍSO RECUPERADO}

Cuando estaba en París, los domingos, arduos, me despertaba a mediodía la luz frágil que entraba por la ventana. (...) Pensaba, fumando, apoyado en la baranda de un puente antiguo, que había en el mundo una casa que era la mía, con palmeras y un sol obsceno, carnal, resbalando sobre las hojas de los paraísos. De chicos, hacíamos collares de flores lilas, y mordíamos las hojas frías y amargas. Yo estaba en el mundo, vivía en el extranjero, y había un camino verde hasta un punto pleno y festivo que era mi hogar. Caminaba plagado de nostalgia y deseo hasta que anochecía.

Ahora he vuelto, la pesadilla de París, ciudad que pertenece a otros, se ha borrado. Hoy es la noche del viernes, en pleno verano. Estoy sentado en una mesa de madera clara, bajo la lámpara. (...). Cuando llegue el domingo, (...) ¿qué otro lugar habrá en el mundo, para que yo quiera — nudo de deseo y de nostalgiaestar en él y no aquí? 1969. (2013:28)

Entre los procedimientos de escritura saerianos, la utilización de vocablos polisémicos es unos de los más estratégicos porque se propaga a lo largo de toda su producción. Esto crea relaciones hipertextuales que permiten al lector multiplicar las imágenes, es decir, los sentidos. La persistencia en la construcción de un universo diegético consolida ese procedimiento; «El paraíso recuperado» es, a partir de la elección del título y del registro lingüístico, un texto ficcional o, en todo caso, que ficcionaliza una experiencia personal. El nudo de reflexión es el deseo puesto en un lugar distante. Esta imagen sintetiza el movimiento de la experiencia del exilio (la distancia necesaria entre lo vivido y su intelectualización) y de su escritura (la posibilidad de ficcionalizar la experiencia).

En la primera anotación del Cuaderno 7 ( 22 de julio de 1968»), la escritura y la lectura se vuelven imposibles. En la nota «El paraíso recuperado», sin embargo, se observa el intento de una escritura de la experiencia de lo extranjero. Y en los textos posteriores de Saer, esta distancia inabarcable pasará del orden espacial al orden temporal. Ya no se tratará de un lugar físico, sino de un lugar del pasado («lo que cambia el objeto, pero no el problema»). Esta tematización de la condición de exiliado que es intrínsecamente la condición del hombre.

Desde el título, el regreso imposible está presente: «El paraíso recuperado» hace eco en la flora de la Zona y en la búsqueda de $A$ la recherche du temps perdu, hipotexto prustiano. Por un lado, un árbol 
de la región dejada y de un espacio, en el imaginario cristiano, perfecto por venir, pasado y futuro que se agota en el gesto de recuperación, que se adivina imposible: «otros, ellos, antes, podían». ${ }^{5}$

«El paraíso perdido» está precedido por notas preparatorias para un proyecto de novela titulada «Continuo», como dijimos.

\section{PARA CONTINUO}

Primero la creación del mundo; luego, la caída.

El eje de la novela: el personaje del niño que cae del árbol (un paraíso) en un jardín el primero de enero de 1901. Ha recibido una «herida», producto de unas maniobras militares. A lo largo de la novela trata de ser indemnizado por esa «herida». Fin del libro sobre la puerta del tribunal que se cerró. (2013:21)

Las notas que siguen a estas líneas se ofrecen así: un grupo que detalla el tratamiento de los personajes, otro que detalla el tratamiento del espacio diegético, y un tercero la estructura. En lo que concierne a los personajes: «deben aparecer, sin excepción, todos los personajes y todas las situaciones que aparecen en mis cuentos y novelas anteriores», «deben aparecer personajes reales, históricos, junto con los personajes ficticios» (2013:23). Luego, respecto del espacio diegético: «Todo el mundo, incluso todo el universo, debe entrecruzarse en el lugar de la novela: la ciudad y su zona de influencia» (23). Por último, a propósito de la estructura: «absolutamente realista», «muy pocos diálogos» (24).

En el mundo de la música, el continuo designa la fracción de la partición en donde la base, subyacente y continua, crea una melodía de fondo a partir de una principal. Entre las notas preparatorias de esta novela, lo continuo se manifiesta en la voluntad de representar las totalidades: «todo el mundo, incluso todo el universo», «todos los personajes», «todas las situaciones» y cuyo contrapunto, o melodía principal, es la del niño que se cae de un árbol. «Continuo» era también el título de una antología de poemas no publicados y de una primera versión de Lo imborrable. Si observamos los dos proyectos de novela («Continuo» y «Las aventuras de Tomatis»), la primera sugerencia que podemos hacer es justamente la reiteración del personaje Tomatis, de quien Saer se ocupará intensamente, como dijimos, en la novela Lo imborrable (1993). Allí Tomatis sale poco a poco de una depresión, divorciado de una mujer que rechazó refugiar a la «Tacuara» vecina y actualmente desaparecida por la dictadura militar como algunos de sus propios amigos.

Existen continuidades entre la gran novela de Tomatis y este primer periodo de exilio en el que pusimos énfasis con algunos ejemplos. Son formas germinales, de elaboraciones tentativas, pero constantes; en la versión editada, el subtítulo «Continuo» se incrusta como una de las notas paratextuales. La distancia temporal entre esos dos momentos de escritura se manifiesta en la idea de aquello que para el autor era continuo y de cómo se aparecía. En la novela publicada en 1993, el continuo es «la expansión que no para» e igualmente «de lo que no alcanzó a ver más que lo fragmentario", lo discontinuo.

La distancia entre los textos de 1968 y Lo imborrable no es solo una distancia de reelaboración de la experiencia íntima del exilio, sino también de una experiencia colectiva traumatizante. Aquello que se vuelve relato ordenado de la experiencia no muestra más que lo que queda: un Tomatis devastado. A partir de la misma relación entre el continuo y la melodía principal, la dictadura militar es el continuo en contrapunto de la historia de Tomatis, lo subyacente, lo imborrable. O como apunta Ilse Logie, «Lo imborrable designa simultáneamente la cristalización de la negatividad del terror de la dictadura en algo positivo: un proceso de escritura» (11-38, 24). 
La reescritura de las distancias temporales y espaciales, la experiencia en el extranjero, el exilio voluntario en el 68 y luego el miedo de volver entrañan no sólo el presente en Francia sino también el pasado en Argentina. Es notable cómo la búsqueda de nuevas estrategias de escritura no obedece necesariamente a un cambio de estilo, sino también a un cambio de orden vital. Entre las escrituras de esa época se transmite la experiencia de la pérdida y del desarraigo, de la suspensión del tiempo, de la extrañeza de la lengua... y de fondo, lo que continúa es un desplazamiento perceptivo forzado, cuya duración e intensidad eran, en ese entonces, desconocidas.

\section{El caso Moyano: ejemplos de una escritura interrumpida}

Con respecto a la obra de Moyano, el cruce de las temporalidades de escritura y de archivo no sólo nos permitió analizar procesos redaccionales antes desconocidos, sino que fue indispensable para dimensionar el peso de las interrupciones en su itinerario de escritura. Y lo más llamativo es que la forma del Archivo Moyano ha propiciado esto con su evolución no siempre atada a documentos redaccionales y pre-redaccionales relacionados con borradores o apuntes. El caso Moyano, dentro de la misma perspectiva metodológica, es completamente distinto al de Saer: la construcción, con los documentos de archivo, del mapa de génesis de escritura da cuenta de ello, además de su búsqueda estética distinta y de la distancia en las formas de construcción del objeto (que sin embargo persigue la idea del paraíso y la fantasía de su recuperación).

\begin{tabular}{|c|c|c|c|}
\hline Publicado & Título y acrónimo & Proceso genético & Lugar de edición y editorial \\
\hline 1956 & El durmiente & $i ?$ & Tucumán, La Gaceta (cuento) \\
\hline 1960 & Artista de variedades (ADV) & ¿? & Córdoba, Assandri \\
\hline 1963 & El rescate $(\mathrm{ER})$ & ¿? & Buenos Aires, Burnichón (cuento) \\
\hline 1964 & La lombriz (LL) & $i ?$ & Buenos Aires, Nueve 64 \\
\hline 1966 & Una luz muy lejana (ULML) & $i ?$ & Buenos Aires, Sudamericana \\
\hline 1967 & El fuego interrumpido (EFI) & ¿? & Buenos Aires, Sudamericana \\
\hline 1968 & El oscuro (EO) & ¿? & Buenos Aires, Sudamericana \\
\hline 1970 & Mi música es para esta gente (MMEG) & $i ?$ & Caracas, Monte Ávila \\
\hline 1974 & El estuche del cocodrilo (EEDC) & $i ?$ & Buenos Aires, Ediciones del sol \\
\hline 1974 & El trino del diablo (ETD) & ¿? & Buenos Aires, Sudamericana \\
\hline 1981 & El vuelo del tigre (EVT) & ¿1974?-1981 & Madrid, Legasa \\
\hline 1983 & Libro de Navíos y Borrascas (LNB) & $1981-1983$ & Buenos Aires, Legasa \\
\hline 1988 & $\begin{array}{l}\text { El trino del diablo y otras } \\
\text { modulaciones (Trino) }\end{array}$ & $1987-1988$ & Barcelona, Ediciones B \\
\hline $\begin{array}{l}1989 \\
1990\end{array}$ & Tres golpes de timbal (TGT) & ¿1976? 1985-1987 & $\begin{array}{l}\text { Madrid, Alfaguara } \\
\text { Buenos Aires, Sudamericana }\end{array}$ \\
\hline 1999 & Un silencio de corchea (USC) & $1987-1988$ & Oviedo, KRK \\
\hline 2005 & Dónde estás con tus ojos celestes & 1988-1992 & Buenos Aires, Gárgola \\
\hline
\end{tabular}




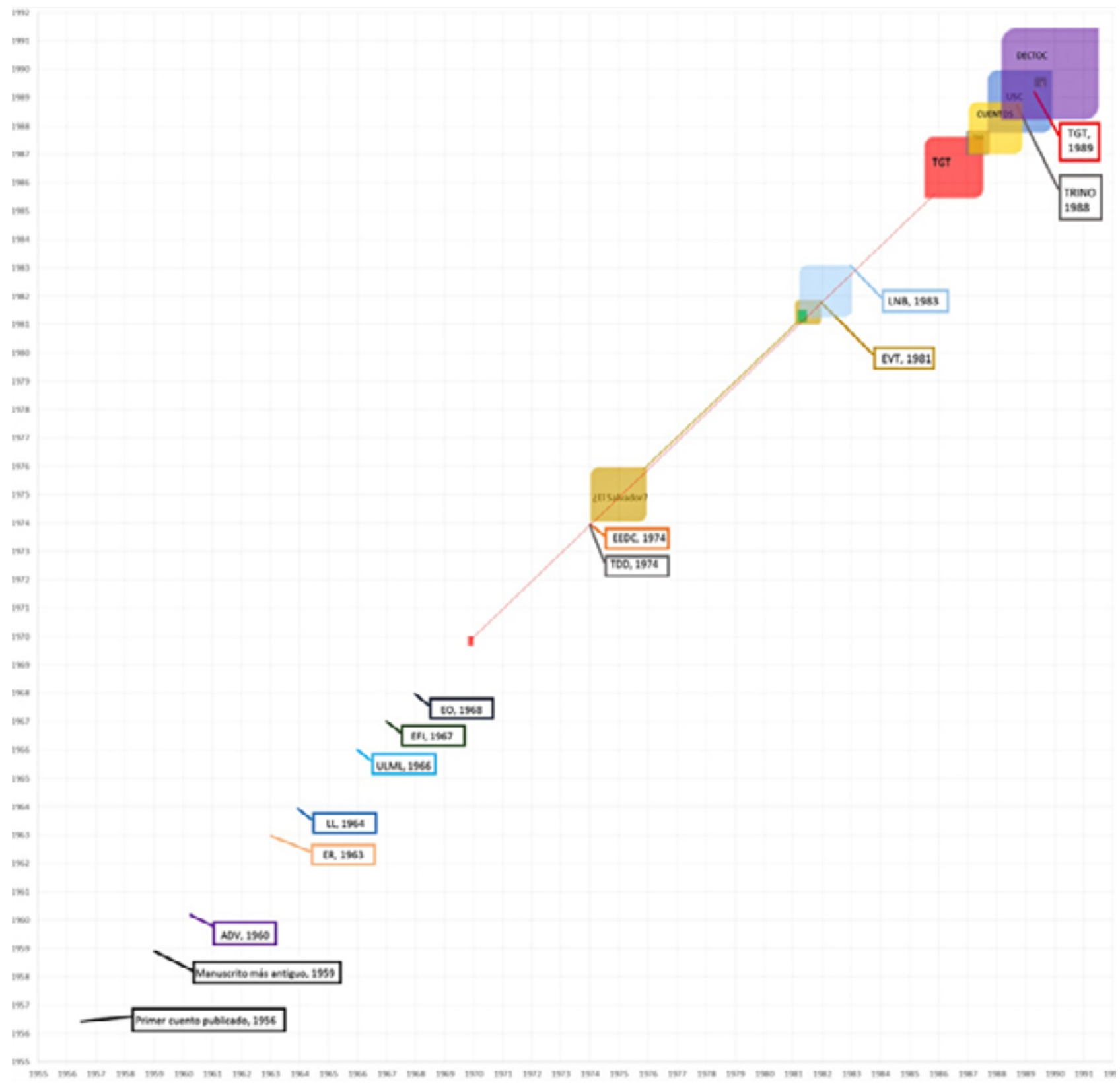

Antes de 1981 no existen documentos que den cuenta de cómo Moyano escribió sus textos. La presencia de El salvador, representado como un proceso redaccional que abarcó de 1974 a 1976, sólo puede ofrecerse a partir de testimonios del autor; no existe documento pre-redaccional que lo respalde. Según Moyano, ese texto fue enterrado por unos amigos en la huerta de su domicilio, en La Rioja, tiempo antes de exiliarse, y luego lo reescribió por completo en Madrid bajo el nombre de El vuelo del tigre, publicado en 1981. Aquí ya se imponen algunos interrogantes: con semejante pérdida, y atendiendo a la sufrida vivencia del exilio, ¿qué es interrupción y qué es escritura, en Moyano? ¿Se puede decir que El vuelo del tigre es la reescritura de un texto que enterró cinco años antes en una huerta? Más allá del testimonio, ¿se lo puede pensar así? Después retomaremos la importancia del ejercicio de la reescritura en su obra, sobre todo a partir de 1987, cuando adquirió su 
primera computadora. Pero como se ve en el mapa, en ese mismo año (1981) también se observa un pequeño rectángulo verde: fue la única forma de ilustrar lo que Moyano llamó «el regreso a la escritura», esto es, la redacción de un cuento («Tía Lila»), empujado por un artista amigo, que le permitió comenzar a recuperar su voz. El desarraigo y el trauma de la cárcel habían marcado en Moyano la pérdida del lugar simbólico de la escritura ${ }^{16}$ (Casarin 2012), y ese evento que consideró decisivo se ofrece como un recomienzo de su decir, ya que inmediatamente después se abocó a El vuelo del tigre y en simultáneo a su novela más cruda sobre su condición de exiliado: Libro de Navíos y Borrascas.

Otros ejemplos también son elocuentes para reforzar la idea de una escritura interrumpida. El germen de lo que sería la redacción de Tres golpes de timbal se encuentra muchos años antes, en un cuaderno argentino fechado en 1976 que llegó a conservarse entre sus papeles. Allí había anotado, con un tono similar al de Saer en sus anotaciones sobre "Continuo», que el punto de partida de la novela sería un hombre simple y solo "que se exprese desde su inocencia», con un objetivo a desplegar: «demostrar que la historia, toda la historia humana, no es nada más que una penosa repetición, una absurda reiteración", y haciéndolo a partir de un "tono» a trabajar: «De allí que además del tratamiento épico, lírico, y poético del asunto, también habrá tratamiento de sicología profunda, que es donde me siento más cómodo» (Demarchi 2012:49). Esa vieja idea para escribir su «novela sobre La Rioja» giraba alrededor, como afirmó Demarchi, de Facundo Quiroga, caudillo riojano asesinado en 1835 y protagonista del libro más conocido de Domingo F. Sarmiento. Lo cierto es que la escritura del texto comenzó a mano en septiembre de 1985, en otro cuaderno español. Y ese mojón marca el fin de una larga traba para la escritura del autor: recién en ese año logró dejar un empleo de 9 horas diarias que arrastraba desde años atrás. De allí surge, como se ve en el mapa, el blanco entre los años 1978 y 1984, durante los que pudo reescribir aquel texto enterrado y redactar Libro de Navíos y Borrascas. Una vez liberado de esa extendida rutina laboral, puede observarse la última y más prolífica etapa de producción, hasta su fallecimiento en 1992, que comenzó con el obsesivo trabajo de Tres golpes de timbal ya abordado en otros estudios críticos (Casarin 2012, Vigna 2012) y tuvo entremedio la reescritura de muchos de sus cuentos publicados en Argentina (Demarchi 2015) (reescritura que no pudimos terminar de explicar hasta el descubrimiento de nuevos documentos de archivo), así como también la reescritura completa y parcial de algunas novelas (El trino del diablo, publicada por primera vez en 1974, fue reescrita; El oscuro, de 1968, quedó por la mitad).

El origen de la escritura de Tres golpes de timbal acerca a Moyano con Saer desde contextos diferentes. Como se vio antes con algunos ejemplos del santafesino (el íncipit de la novela Nadie nada nunca), en algunos procesos ambos fueron capaces de retomar, modificar y elaborar un texto a partir de ideas y frases aisladas. En Saer, casi como una ética; en Moyano, casi como un accidente.

Pero antes de profundizar en otros ejemplos destacamos la influencia de la ampliación del Archivo para dilucidar estos procesos. En 2009 se relevaron y organizaron los papeles que Moyano dejó en su archivo personal de Madrid. Entre ellos no había, como dijimos, documentos preredaccionales relativos al periodo argentino; apenas una versión preliminar anotada de El trino del diablo (1974) y una versión de su primera novela, inédita, Los pájaros exóticos. Sin embargo, aun frente a ese silencio de años, posteriores ampliaciones del archivo llevaron a echar luz sobre procesos redaccionales específicos, en una indagación lateral sobre la génesis de sus ficciones. $\mathrm{Al}$ archivo original se sumó en 2013 la inclusión del archivo de fotografías y notas periodísticas del autor, y dos años después una exhumación informática que permitió recuperar archivos de texto almacenados durante 30 años en disquetes obsoletos de una computadora marca Amstrad. 


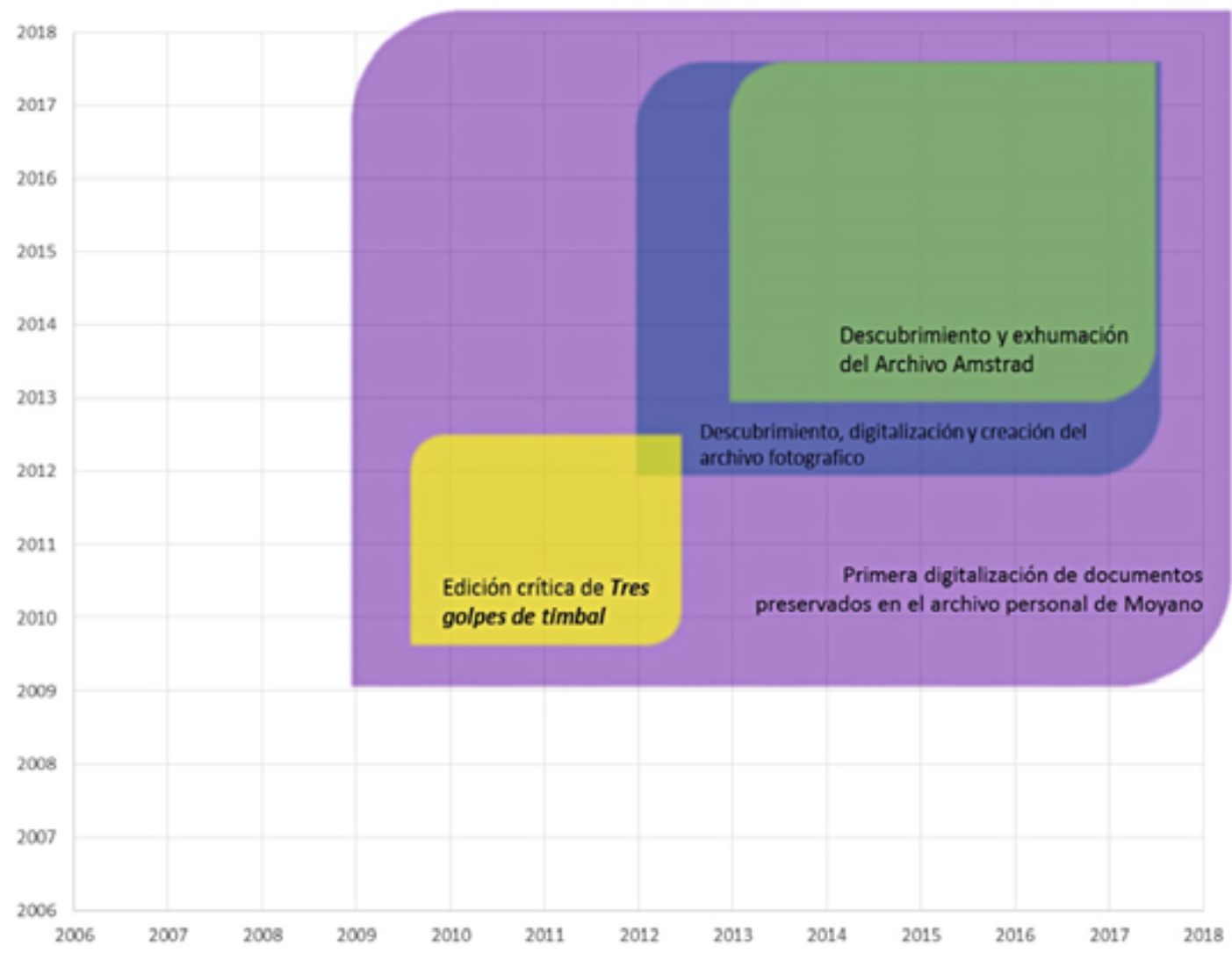

Mapa de evolución del Archivo Daniel Moyano (CRLA-Archivos)

Este mapa no ofrece revelaciones per se; apenas se puede dimensionar de qué forma los descubrimientos fueron alimentando el fondo de origen. Sin embargo, al representar el rango cronológico que cada descubrimiento ocupa (según las fechas de los documentos de cada una de las ampliaciones), fue posible echar luz sobre textos producidos en ese periodo silenciado por el exilio. Al solapar los mapas en un mismo eje toma dimensión la importancia del archivo en la dilucidación de los procesos de escritura. ${ }^{17}$

Fotografías, reportajes, crónicas y disquetes obsoletos pero bien conservados aportaron elementos para traer el pasado hacia el presente desde otros lenguajes, lo que significó una novedad para nuestra perspectiva geneticista y, hasta ese momento, estrictamente literaria. En primer término, la fotografía, conjugada con el desempeño de Moyano como corresponsal del diario Clarín en La Rioja, permitió llenar huecos en procesos escriturales como los de Tres golpes de timbal ${ }^{18} \mathrm{y}$ El vuelo del tigre, y hasta esclarecer la génesis de algunos cuentos como «Cantata para los hijos de Gracimiano» ${ }^{19}$ Esto fue posible a partir de un cruce entre el análisis textual y contextual, testimonios de implicados en la obra y el origen de procedencia de los documentos, específicamente las huellas en la organización de los negativos. Pero los testimonios han sido un elemento fundamental tanto para la pesquisa genética como para la constitución del archivo.

En segundo término, los 22 disquetes obsoletos recuperados ${ }^{20}$ de su biblioteca. Allí Moyano conservó borradores, apuntes, versiones preliminares completas (como el último dactiloscrito de Tres golpes de timbal, la reescritura de El trino del diablo o el original de Un sudaca en la corte), artículos periodísticos, canciones, poemas, y un material decisivo para ampliar la interpretación sobre algunos procesos redaccionales: la correspondencia dirigida a colegas, amigos y familiares. En los 


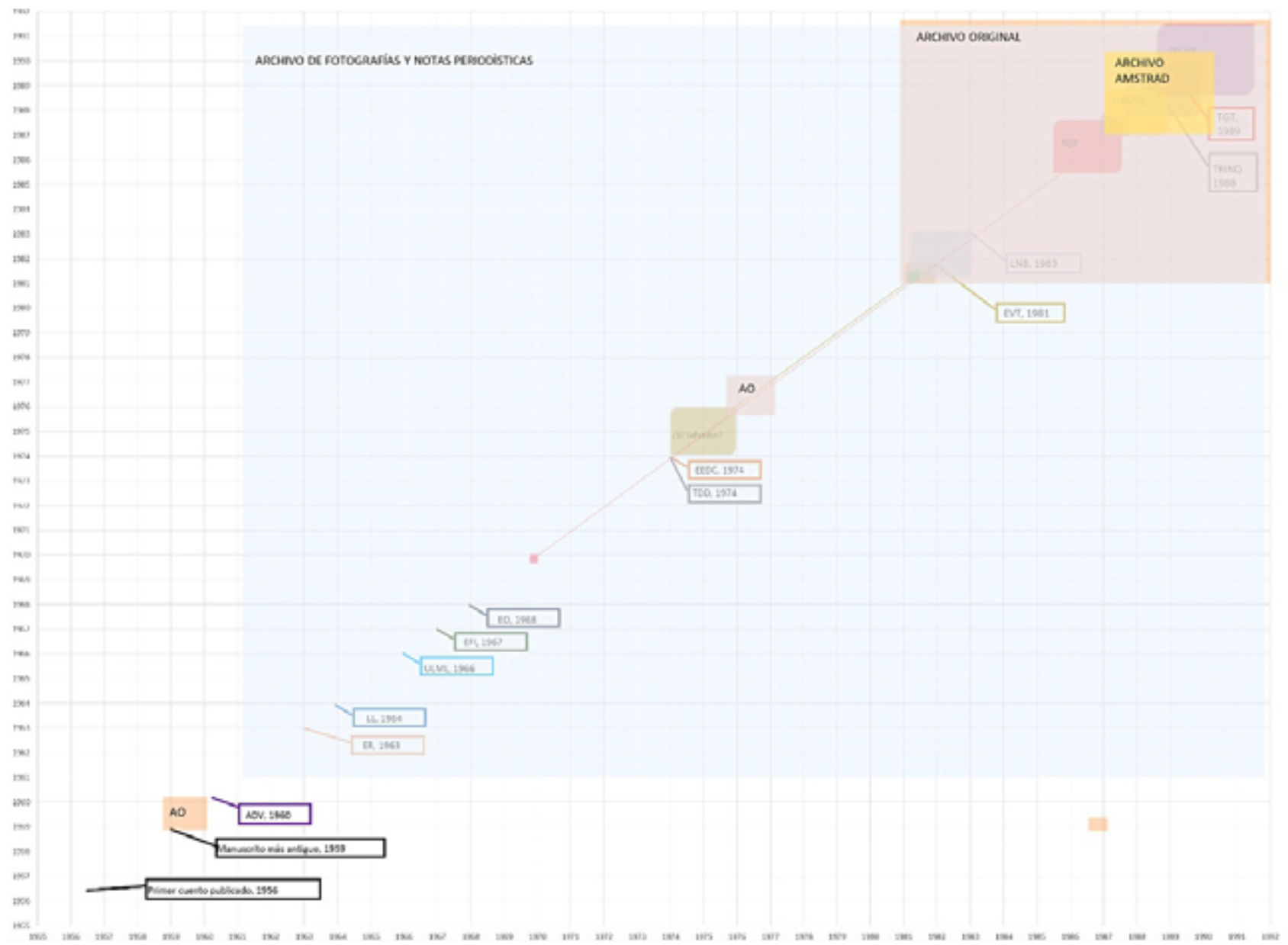

Mapa de génesis de procesos de escritura de Daniel Moyano solapado con Mapa cronológico de las distintas ampliaciones del archivo. En celeste, el periodo que cubre el Archivo de Fotografías y Notas Periodísticas, desde la primera fecha relevada hasta la última; lo mismo para el Archivo original, en rosa pálido, y para el Archivo Amstrad en naranja.

disquetes sí encontramos, por lo tanto, documentos redaccionales y pre-redaccionales como los citados, pero ponemos el foco en la correspondencia ${ }^{21}$ porque allí Moyano da cuenta de ciertas explicaciones que han tenido incidencia en el análisis de estos procesos, como el caso de Un sudaca en la corte, ${ }^{22} \mathrm{El}$ trino o los cuentos rescritos. Las cartas, en estos casos, son reconocibles como material pre-redaccional porque despliegan el germen narrativo de algunos textos. ${ }^{23}$

La exhumación de las cartas reforzó la evidencia de que toda conformación de un fondo documental va más allá de los manuscritos convencionales, fetiches para la genética textual, e involucra diversas textualidades y lenguajes. Las cartas permitieron resolver misterios interpretativos que los documentos redaccionales y pre-redaccionales no: específicamente, por qué Moyano decidió reescribir, en España, casi toda su obra publicada en Argentina. La esfera más íntima del archivo amplió la esfera literaria desde las obsesiones personales y las condiciones técnicas de producción. En los disquetes recuperamos la versión rescrita de El trino del diablo, pero gracias a la correspondencia pudimos saber por qué Moyano tomó esa decisión: en momentos de estar revisando la traducción del texto al inglés, creyó que debía corregir cosas y terminó reescribiéndolo por completo. La presencia en los disquetes de una reescritura interrumpida de la novela $E l$ oscuro tampoco tenía explicación, al igual que varios cuentos: bastó recurrir nuevamente a los testimonios para acercarnos a una respuesta. 
La sospecha más fuerte en torno a las rescrituras, antes del Archivo Amstrad, era que la condición del «exilio eterno», como Moyano lo llamaba, y la carga nostálgica consecuente, lo empujaron a releer sus textos, a recobrar su experiencia a través del trazo, a repasar la vida a través de la palabra inscrita. Sin embargo, en una carta escribió:

Para distraerme, y aprovechando las ventajas del procesador de textos que tengo, reescribo lo viejo. Prácticamente todo. (...) La reescritura de aquellos trabajos se debe a que, como no conservo los originales, me he visto obligado a pasarlos otra vez a máquina, es decir, meterlos en la memoria del «computer». He escrito de nuevo cuentos como «La lombriz» $\mathrm{y}$ «Los mil días», y ahora estoy con una nueva versión de «El oscuro». Ya que tengo que pasarlo otra vez en limpio, aprovecho para quitarle las tonterías que dije antes y agregarle las que digo ahora. ${ }^{24}$

Esta confesión se repite en otras: como sólo tenía el resguardo del papel, decidió transcribir sus textos a la memoria de la computadora, más fiable. Y como los transcribió, los reescribió. La paradoja lleva a confirmar que no sólo reescribió por nostalgia o desarraigo: buena parte de la energía que puso en esa obstinación ha sido producida por el entusiasmo que le provocó el contacto con la máquina, la novedad eclipsante del soporte y de la memoria paralela. ${ }^{25}$

Hay una paradoja técnica que recubre a estos procesos. Es cierto que los descubrimientos del archivo permitieron acceder a nuevos documentos al ventilar nuevos restos, pero eso se basó en recuperar archivos de una computadora, muchos de los cuales habían sido impresos antes (otros no). En el marco de un recorrido escritural con tantas interrupciones, la recuperación de archivos permitió ampliar la reconstrucción temporal de la escritura de Moyano pero no a través de sus manuscritos (apuntes y versiones preliminares), sino a partir de la lectura de la correspondencia. La paradoja se basa en que el trabajo genético se empobreció con la irrupción informática, y a la vez revalorizó los procesos realizados en etapas anteriores a partir de papeles propiamente dichos. El archivo se amplió con documentos informáticos que dieron más relieve a la materialidad de los pocos documentos conservados.

\section{Cierre}

Entre las temporalidades de la escritura y las temporalidades que organizan el archivo, la distancia se agranda en cuanto lo que interviene no es lo material de la obra, sino lo vital de la experiencia. En este sentido, los criterios de conservación material de los documentos (ordenados alrededor de obras editadas) no son suficientes para dar cuenta de aquello que tiene lugar entre papeles sueltos. De este modo, en el caso de Saer, la primera conclusión corresponde al interés de leer su archivo a la luz de ciertos acontecimientos personales precisos ya que cuando la escritura se dispersa, se destruye, cuando no se puede escribir, el protocolo que ordena el archivo Saer es incapaz de volverlo visible. El mapa permite observar esos huecos y guía la búsqueda de respuestas. Con respecto a 1968-1969, una de las pistas fue dada por Miguel Dalmaroni, que observa y analiza este vacío a partir de la recepción de la obra:

El tópico del silencio no merece una explicación únicamente biográfica, pero la tiene: el traslado a Francia en 1968. (...) Saer se fue a París no para que el ruido con que su escritura disonaba en la literatura argentina se amplificase sino, muy por el contrario, para asordinarse. (619) 
De modo que estos años de repliegue y de reelaboración de la escritura se ven marcados por otro tipo de silenciamiento: la desaparición del autor de la escena literaria argentina a causa de ediciones agotadas seguidas de ediciones extranjeras cuya distribución era restringida. Esto aumenta el efecto de lectura de una parte de la crítica literaria que, a fines de los años 70 pero sobre todo a partir de la vuelta de la democracia, reubica la figura de Saer en el campo literario argentino. El silencio, el corte, la distancia potenciaron la escritura por venir. Cruzar las dos temporalidades, de escritura y de archivo, permite analizar estos momentos de elaboración, de dinámica escrituraria. Esto mismo da cuenta del rol que el exilio ha tenido en su escritura ya que la divide irremediablemente en un antes y un después. Entre los documentos estudiados, se observa que la textualización de una distancia de ahora en más irrecuperable permite preparar el terreno de la obra por venir.

En el caso de Moyano, destacamos que en sus últimos años de vida creyó que podría ser, de una vez por todas, un escritor profesional. Los avances informáticos le permitieron agilizar su escritura en ese sentido: escritura que, en su caso, es siempre reescritura, incluso desde que constatamos las correcciones que hacía en sus libros ya publicados. Pero el ingreso al mundo informático, como complemento de la atención editorial que comenzó a recibir en España y de su acercamiento al olimpo de los agentes literarios (sobre todo por su conflictiva relación con Carmen Balcells), le permitió comenzar a producir con la velocidad necesaria como para materializar ideas acumuladas. Rogelio Demarchi plantea una teoría de la reescritura en Moyano: asocia esta situación en su recorrido vivencial y literario con su misma esencia de narrador obsesivo. Estos procesos no serían más que su paso de ser un contador (hay innumerables referencias a su práctica de la literatura oral; «contaba oralmente sus relatos varias veces antes de considerar definitivo un texto» y, es más, «conservaba tan sólo aquellas historias que resistían el juego de la narración oral»), a ser el escritor que pretendía ser.

Esto mismo da cuenta del efecto vertebral que ha tenido el exilio en su obra. No sólo desde la crítica, con sus temas, sus limitaciones y obsesiones que a partir de su regreso a la escritura en España vivieron un cambio notable desde el punto de vista estilístico, sino también desde su abordaje genético. La última dictadura argentina influyó directamente tanto en la conservación como en la constitución de su archivo. Moyano se fue borrando o, mejor dicho, lo fueron borrando de tal modo que esto impactó en su misma cotidianeidad, además de impactar en su visibilidad editorial.

La construcción de un modelo gráfico nos permitió dar cuenta de zonas que ilustran los procesos ejecutados al interior de una obra y de un archivo. El desafío es corroborar si un modelo así puede ser extensible a otras escrituras y fondos documentales, así como indagar qué sucede en otras obras cuando se ensaya una articulación entre la temporalidad de la escritura y la temporalidad de la organización de un archivo (esto último pensado como una reescritura forzada por archivistas). El valor de confeccionar un mapa parece estar en el reconocimiento o no de una cadencia. Ver cómo los autores van marcando una secuencia, regular o estertórea, de la escritura, que desde la intimidad parece oponerse (con mayor o menor violencia) a su materialización editorial. Todo mapa se vuelve más atractivo cuantos más huecos ofrece, por un lado, o cuanto más ruido ofrece en términos cromáticos. Los interrogantes profundos han surgido cuando no hay color, o cuando se vuelve confusa la suma de colores (procesos escriturales superpuestos).

Junto a esto, podemos pensar cómo se desenvuelve el valor de archivo si lo disponemos en el espacio. ¿Qué sucede si ilustramos las modificaciones de un archivo a partir, primero, del acceso 
a los documentos, y luego de cómo esos documentos permiten transitar por el mapa de los procesos escriturales? Un autor «aplicado» (esto es, una acción premeditada) empobrecería el trabajo genético. Así volvemos a lo que motoriza tanto la crítica genética, como la teoría y práctica sobre archivos: aquello que no está, y que probablemente no estará nunca.

En un clima de época en el que la publicación es exaltada como nunca antes (los autores pretenden aparecer en el mercado editorial cada vez más rápido; los autores precisan observar el producto de su trabajo, esté logrado o no), la materialización editorial de los procesos escriturales no parece tener demasiada importancia para el análisis crítico-genético. La escritura no está destinada a finalizar porque no es lo que se busca. Aunque suene obvio, la escritura opera como definición de la temporalidad propia; paradoja intuida, o verbalizada, pero real. En algunos ejemplos (habrá que ver si esto puede extenderse a otros autores, a otros archivos), hasta podría decirse que probablemente no haya nada que diga menos de la escritura de un autor que la publicación de sus libros, lo que sin embargo es el origen de las intuiciones del investigador, del archivista, del interviniente.

\section{Notas}

1 En Éléments de critique génétique, Almuth Grésillon señala que toda génesis de proyecto tiene tres fases: una fase preredaccional (búsqueda de documentos, notas, esbozos...), una fase redaccional (etapas de elaboración textual) y una fase de puesta a punto (copias definitivas poco corregidas). Algunos años más tarde, Pierre-Marc de Biasi (31-60) establece una tipología de documentos de génesis en donde detalla los estadios, las fases, las funciones operatorias y el tipo de documentos que componen un dossier genético.

2 El mejor ejemplo en el caso de Saer es el proceso de génesis de El limonero real, en el que las primeras textualizaciones comienzan en 1964 aunque no se trate de la redacción definitiva.

3 Este proyecto saeriano hace parte de la tesis doctoral de Verónica Bernabei, defendida en el mes de diciembre de 2017, en la que se trabajan puntualmente estos casos. Cuando hablamos de núcleos narrativos nos referimos a algunas ideas que vuelven a lo largo de los años, a veces bajo la forma de una frase, a veces bajo la forma de un argumento o de una imagen.

4 Es el caso de los «desprendimientos» narrativos que tienen lugar durante el proceso de génesis de La grande (2005) a lo largo de más de veinte años. Nos referimos a la novela Lo imborrable (1993) y al cuento «En línea», incluido en Lugar (2000). Consultar en Verónica Bernabei, «El tiempo en astillas. Reflexiones en torno a las intervenciones del autor sobre su archivo a partir del dossier genético de La grande (2005) de Juan José Saer» (2018).
5 Se puede consultar un análisis detallado en la tesis doctoral de Verónica Bernabei, en curso de traducción.

6 Saer declaraba: «Cuando estoy escribiendo algo, ya estoy pensando en lo siguiente que voy a escribir» (Saavedra:114).

7 La datación de los procesos genéticos que se detallan a continuación es producto del análisis del Archivo Saer, y de lo establecido por Juan Premat en los estudios críticos publicados en J. J. Saer (2010, 2012, 2015).

$8 \mathrm{El}$ primer boceto de íncipit fechado el 19/11/71 se encuentra en el Cuaderno 8, J. J. Saer (2013:60). En lo que concierne la segunda fecha (1973), tuvimos en cuenta un borrador de entrevista que aparece en el volumen de Ensayos: «en el 73 empecé Nadie nada nunca y la terminé en febrero de 1978» (Saer 2015:133-134, 159).

$9 \mathrm{El}$ primer boceto de íncipit está fechado el 5/4/78. Ver Saer (2013:125). Con respecto a la fecha de fin de escritura, ver lo detallado por Premat en Saer (2010:467) y Saer (2013:239-245).

10 Tres libros de cuentos: En la zona (1960), Palo y hueso (1965), Unidad de lugar (1967) y dos novelas: Responso (1964) y La vuelta completa (1966). Para más detalles ver cuadro.

11 Escrita en 1967 y publicada en 1969 en Buenos Aires por la editorial Sudamericana.

12 Declara: «Poco a poco empecé a entrar en una especie de solipsismo literario, que se agravó mucho cuando me fui a Francia, donde no conocía a nadie. Ahí estaba en el medio de otro idioma, no tenía editor. Sí, mi último libro que se editó en Argentina al año siguiente de mi partida fue Cicatrices, en 1969. 
Y después, a partir de ese momento, no volví a publicar un solo libro en la Argentina. Mi siguiente libro, El limonero real, se editó cinco años más tarde en España, en 1974. En Francia estaba totalmente solo y no tenía a quien leerle, y tampoco tenía ganas de leerle a nadie. Estaba en una zona de incertidumbre respecto del valor posible de mi trabajo. Pero, al mismo tiempo, nunca le mandé un libro a un crítico, nunca le mandé un libro a una revista. Yo quería que el reconocimiento viniese espontáneamente del exterior» (Saavedra:102-103).

13 Por una cuestión de facilidad de acceso a los documentos, remitimos a la descripción de cada cuaderno que propone Julio Premat en la edición de Borradores inéditos. La referencia de documentos manuscritos alojados en la biblioteca de Princeton no es exacta y su acceso es, por razones evidentes, más restringido. Por otro lado, en los casos citados, la transcripción de Borradores coincide con el documento original. El «cuaderno 7» y el «cuaderno núcleo I» se encuentran en Saer (2012:241-246 y 253-336). Las «Hojas sueltas I (fines de los 60 y años 70)» se encuentran en Saer (2013:19-59).

14 La estructura definitiva de Lo imborrable representa la incrustación de lo fragmentario en el continuum narrativo. En la novela, las referencias marginales representan, no tanto un resumen de la historia principal, sino más bien su forma breve, es decir, el momento antes del despliegue narrativo. Se trata de expansiones de fragmentos que era «(otro título posible)».

15 Referencia al íncipit de la novela de Saer Nadie nada nunca, México, Siglo XXI, 1980.

16 Moyano dijo haber perdido a sus personajes, las historias que eran la carnadura de sus ficciones. Y su reencuentro con la escritura fue relatado de este modo: «Un día vino un amigo que es médico y pintor, Osvaldo Gomáriz, y me dijo: "yo tengo un remedio para vos". Creí que me iba a dar unas pastillas y le dije que no quería saber nada. Pero él me dio la llave de su buhardilla y me hizo ir a visitarlo: y prácticamente me obligó a escribir. (...) Yo ya no creía en nada y le tenía miedo a volver a creer en la literatura. Además habían pasado muchas cosas en el país, en mi vida, y bueno, yo no me considero un escritor realista y por lo tanto no sabía qué hacer. (...) Así que me planté y le dije a Osvaldo: “Mirá, yo no tengo más tías, y solamente sé escribir sobre mis tías, así que planto y se acabó". Entonces él me dijo: "Ah, bueno, yo tengo una, te la presto". (...) Y se produjo como un pinchazo en esa bolsa de angustias que yo tenía adentro y por el agujerito empezó a salir el cuento...». Consultar en Giardinelli.
17 Ver, como ejemplo de esto, el trabajo realizado en Los desvalidos. Fotografias, ficciones y textos periodísticos de Daniel Moyano (Vigna 2017).

18 Ver la crónica «La muerte de Fábulo Vega y su pobre entierra», publicada en Clarín, Buenos Aires, el 29 de marzo de 1973.

19 Ver el «El interior del interior», en Los desvalidos. Fotografias, ficciones y textos periodísticos de Daniel Moyano (Vigna 2017).

20 En los rótulos de los disquetes hay referencias a novelas: Tres Golpes de Timbal I-II Versión definitiva, El trino del diablo, En la atmósfera; y otras relacionadas con cuentos: Cuentos rescritos, La lombrizy otros cuentos, Musicalia, María violín, Halcón verde y la flauta maravillosa, etcétera.

21 Antes de los disquetes, la correspondencia del autor en el archivo se restringía a las cartas recibidas en papel, conservadas en Madrid, y unas pocas de su autoría donadas por terceros.

22 A partir de una invitación que recibió Moyano para acudir a un evento presidido por los reyes de España, escribió una carta a su hijo Ricardo (25/2/1988) en la que reflejaba la expectativa de asistir, utilizando como motor reflexivo (y como recurso narrativo) su origen mestizo y su torpeza para con los protocolos y formalidades. Allí es posible encontrar el tono de la complicidad familiar, pero también el germen de un relato, un cierto envión narrativo con temática definida, que después de sucedido el evento (la visita al Palacio Real de Madrid) habría de quedar asentado en una crónica que Moyano escribió para un periódico español, y que luego expandió en unos 60 folios (según otra carta) bajo el título de Un sudaca en la corte. El destino editorial de esa experiencia mantuvo el título y fue publicado como nouvelle en 2013. Pero en la carta a su hijo ya se prefiguraba, sin pulir, el registro que sostuvo la narración desde sus primeros esbozos.

23 Para fundamentar la consideración de las cartas como documentos pre-redaccionales basta con recoger algunos señalamientos metodológicos: Lois (2001), por ejemplo, destaca en torno a los materiales pre-redaccionales y también redaccionales que el objetivo es señalar factores determinantes de procesos, 0 huellas que den cuenta de un descubrimiento de posibilidades y potencialidades. Las cartas operan como pretextos preparatorios y en algunos casos como híbridos, teniendo en cuenta elementos que se reiteran en borradores ulteriores: muchas han cumplido la función del descubrimiento de la potencialidad de ciertas experiencias, como Un sudaca en la corte. Si como afirma Lois, la escritura es huidiza, no unidireccional, eso impide interpretar determinados pasos como si fueran reglas o pautas. Pero 
sí es posible, en cambio, «hablar de un conjunto indeterminado de "estrategias" variables para cada situación, y es para describir y evaluar estas estrategias que tiene sentido la confrontación escritura-texto» (19).

24 Archivo Amstrad de Daniel Moyano. Referencia: (Correspondencia/Amigos/Disco 11/Ofelia.001).

25 Otra hipótesis para la obstinación de la reescritura es lo que Moyano llamó «escribir como si tocara»: al ensayar nuevas formas sintácticas y usos de la palabra en pos de una nueva musicalidad, pudo haber releído todo lo anterior a partir de esa nueva (im)postura. Pero esto no es tan concluyente como su explicación de que el procesador de textos cambió la consideración sobre su memoria, y la discusión del término derrideano sin que eso significara su negación, sino más bien su exacerbación: «guardo para escribir/ guardo para reescribir/ reescribo para guardar».

\section{Referencias bibliográficas}

Archivo Virtual Daniel Moyano. Archivo Amstrad. Centre de Recherches Latino-américaines, Université de Poitiers, Francia. http://www.mshs.univ-poitiers.fr/crla/contenidos/Moyano/Presentacion.html

Bernabei, V. (2017). L'espace de la Zona dans la construction de l'œuvre de Juan Jose Saer. Proposition méthodologique pour l'analyse des dynamiques d'écriture à partir d'un fonds d'archives. Tesis doctoral. Université de Poitiers. En prensa.

(2018). El tiempo en astillas. Reflexiones en torno a las intervenciones del autor sobre su archivo a partir del dossier genético de La grande (2005) de Juan José Saer. En P. Arán y D. Vigna, editorxs. Archivos, artes, medios. Teoría y práctica, Córdoba: Centro de Estudios Avanzados (Universidad Nacional de Córdoba). En prensa.

Casarin, M. (2012). El itinerario existencial de Daniel Moyano. En D. Moyano. Tres golpes de timbal (edición crítica). Colección Archivos. Vol. 64. Poitiers, Francia: CRLA-Archivos, 17-35.

(2017). Palabras y música en la literatura de Daniel Moyano. Presentación en D. Moyano. Mi música para esta gente (cuentos completos). Córdoba: Caballo negro, 11-15.

Dalmaroni, M. (2010). El largo camino del «silencio» al «consenso». La recepción de Saer en la Argentina (1964-1987). En J. J. Saer. Glosa El entenado. Edición crítica. Julio Premat, editor. Poitiers/Córdoba: CRLAArchivos/Alción, 607-664.

De Biasi, P.-M. (1998). Qu'est-ce qu'un brouillon? Pourquoi la critique génétique? Méthodes, théories, París: CNRS Editions, 31-60.

Demarchi, R. (2012). Rastros de una escritura en espiral. En D. Moyano. Tres golpes de timbal (edición crítica). Colección Archivos. Vol. 64. Poitiers, Francia: CRLA-Archivos, 49-70.

(2015). Para una teoría de la reescritura. Revista Escritural, (8). http://www.mshs.univ-poitiers.fr/ crla/contenidos/ESCRITURAL/ESCRITURAL8/ESCRITURAL_8_SITIO/PAGES/Do2_Intro.html

Giardinelli, M. (1988). Al cuento hay que tocarlo en un buen violín y bien tocado (entrevista a Daniel Moyano). En M. Giardinelli. Así se escribe un cuento. Buenos Aires: Capital intelectual, 169-180.

Grésillon, A. (1994). Éléments de critique génétique. París: CNRS Editions.

Herschberg Pierrot, A. (2005). Le Style en mouvement. Littérature et art. París: Belin.

Logie, I. (2013). Introducción y presentación del volumen. En Logie, I., coordinadora. Juan José Saer: la construcción de una obra. Sevilla: Universidad de Sevilla, 11-38, 24.

Lois, É. (2001). Génesis de escritura y estudios culturales. Buenos Aires: Edicial.

Moyano, D. (1964). La lombriz. Buenos Aires: Nueve 64.

(1966). Una luz muy lejana. Buenos Aires: Sudamericana. 
(1967). El fuego interrumpido. Buenos Aires: Sudamericana.

(1968). El oscuro. Buenos Aires: Sudamericana

(1974). El trino del diablo. Buenos Aires: Sudamericana.

(1981). El vuelo del tigre. Madrid: Legasa.

(1983). Libro de navíos y borrascas. Buenos Aires: Legasa.

(1988). El trino del diablo y otras modulaciones. Barcelona: Ediciones B.

(2003 [1968]). El oscuro. Buenos Aires: Ediciones del Sol.

- (2010). Un silencio de corchea. La Rioja: Biblioteca Popular Mariano Moreno.

(2012 [1989]). Tres golpes de timbal (edición crítica). Colección Archivos. Vol. 64. Poitiers, Francia:

CRLA-Archivos.

Saavedra, G. (2005). Entrevista pública a Juan José Saer en el Malba (28/05/2003). En El poeta y su trabajo, (20), 102-118.

Saer, J. J. (1993). Lo imborrable. Buenos Aires: Seix Barral.

- (2010). Glosa/El entenado. Edición crítica. Julio Premat, editor. Poitiers/Córdoba: CRLA-Archivos/ Alción.

(2012). Papeles de trabajo. Borradores inéditos. Buenos Aires: Seix Barral.

(2013). Papeles de trabajo. 2. Borradores inéditos. Buenos Aires: Seix Barral.

(2015). Ensayos. Borradores inéditos. Buenos Aires: Seix Barral.

Vigna, D. (2012). De la tierra al texto. Una escritura en capas. En D. Moyano. Tres golpes de timbal (edición crítica). Colección Archivos. Vol. 64. Poitiers, Francia: CRLA-Archivos, 39-47.

- (2017). Los desvalidos. Fotografías, textos periodísticos y ficciones de Daniel Moyano. Colección

Cuadernos de Archivos N² ${ }^{\circ}$ Poitiers, Francia: CRLA-Archivos. 